\title{
Un exemple de film fixe et sa notice
}

\section{OpenEdition}

\section{Journals}

Electronic version

URL: http://journals.openedition.org/trema/3161

DOI: 10.4000/trema.3161

ISSN: 2107-0997

Publisher

Faculté d'Éducation de l'université de Montpellier

\section{Printed version}

Date of publication: 1 June 2014

Number of pages: $100-102$

ISBN: 1167-315X

ISSN: 1167-315X

Electronic reference

« Un exemple de film fixe et sa notice », Tréma [Online], 41 | 2014, Online since 01 June 2014 connection on 19 April 2019. URL : http://journals.openedition.org/trema/3161 ; DOI : 10.4000/ trema.3161

This text was automatically generated on 19 April 2019

Trema 


\section{Un exemple de film fixe et sa notice}

Livret pédagogique du film fixe : la morue. Office de Documentation par le Film [1953]. Cedrhe 51162

Madame la Directrice,
Monsieur le Directeur,
La mer et sa faune, les travailleurs de la mer
tiennent certainement une place non négligeable dans vos
cours de leçons de choses et d'histoire naturelle et, sans
doute, aussi dans votre enseignement de la morale, car,
de toutes les professions exercées par les hommes, aucune
n'est plus exemplaire que celle des marins et particulièrement
des Terre-Neuvas.
Nous avours done pensé qu'en vous proposant le
film à vues fixes édité pour nous par l'Office de Docu-
mentation par le Film, sur la morue, sa morphologie, ses
conditions de vie, sa capture, sa valeur alimentaire et
culinaire, nous mettrions entre vos mains un moyen
moderne d'illustrer vos leçons.
Ce film a déjà été vivement apprécié dans 32.000
établissementsd'enseignement.
Nous espérons que sa projection recevra dans
vos classes, le même accueil que dans les autres
établissements.
Le Directeur,
P. LiNIEPCE


Film fixe, « La morue », Office de Documentation par le Film, [1963]. Cedrhe : 51162
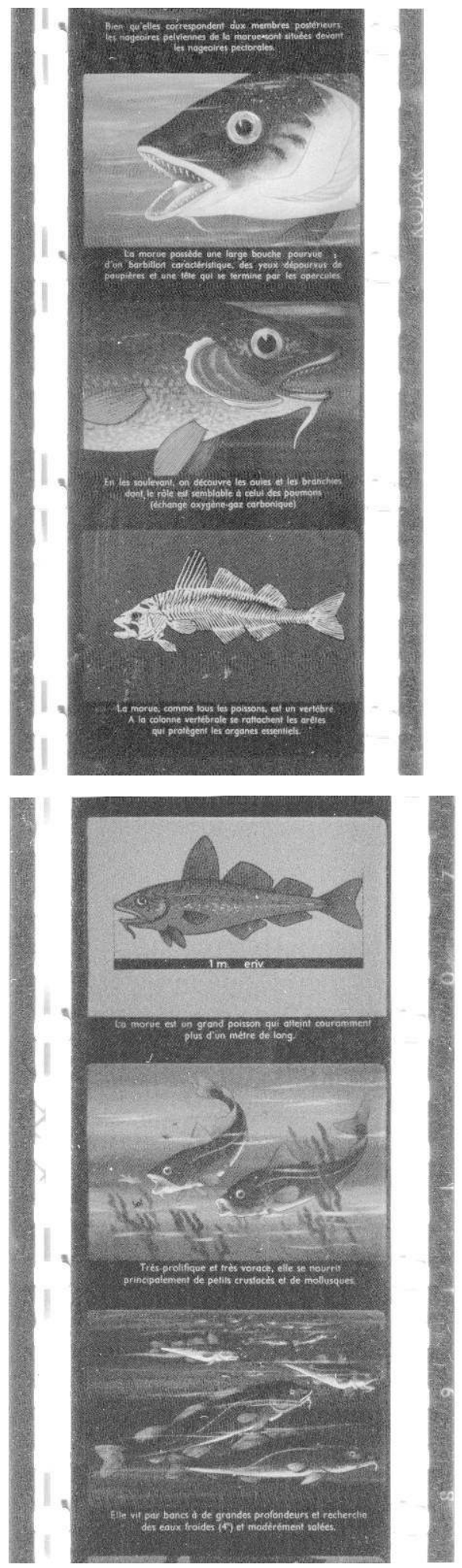